there are very many such small areas, we see that there will be very many species which occupy small areas.

We can obtain, in fact, Dr. Willis's (number of species) against (size of area) curve simply by assuming (I) that in any very large area the distribution of different kinds of environment is random, and

(2) that organisms are adapted to their environment.

I therefore come to conclusions exactly opposite to those of Dr. Willis, for I think we have in his curves direct evidence that :-

(I) Evolution has proceeded almost entirely by natural selection adapting a species to the limitations of its environment.

(2) Animals are so closely adapted to their conditions of existence that it is impossible to conceive of evolution proceeding by the large mutations suggested by Dr. Willis.

Space prevents me considering here Dr. Willis's (number of genera) against (number of species) curves, but these also are susceptible of a similar interpretation in terms of natural selection.

Christ's College, Cambridge, February 16.

$$
\text { C. F. A. Pantin. }
$$

WE find it very difficult to follow the hypotheses made by Mr. Pantin in his interesting letter, and cannot agree that they accord with reality. We cannot see how, for example, the hypothesis that natural selection is the dominant factor affords any explanation of the fact that the numbers and proportions of local species increase towards the south; nor how it can explain the fact that in New Zealand ( $c f$. Ann. of Bot., vol. 32, I9I8, p. 339) a great many families show their maximum number of endemics in every genus at the far north, all these families being IndoMalayan ; while a second group of families, characteristic of the northern hemisphere, show their maximum number at the south of New Zealand, and a third group at the centre. The northern families and genera diminish as one goes southward in New Zealand, and pass over, without paying any attention to, the regions where the maxima of the central and southern groups occur. These groups in the same way show no unusual change when they reach the region where the northern maximum occurs. Are the environmental conditions so peculiar at these points that those of the north should cause a multiplication of species only in Indo-Malayan families, and those of the south only in families of the northern hemisphere?

$$
\text { J. C. Willis. }
$$$$
\text { G. UDNY YULE. }
$$

\section{Columnar Structure in Sandstone Walls of a Glass Furnace.}

IN the issue of NATURE for December 29, I92I, p. 567 , I described the occurrence of columnar structure in optical glass and in fireclay.

Through the courtesy of Mr. Currie, of the Scottish Central Glass Works, Alloa, I had recently an opportunity of examining columnar structure that had developed in the lowest sandstone course of the side walls of a small tank glass furnace. The walls comprised two upper courses of fireclay blocks, in which no columnar structure developed, and the bottom course of rough-grained sandstone blocks obtained from the Penshaw Quarries, Durham. Their crosssection was about $\stackrel{\Upsilon}{\mathrm{s}}$ sq. ft. Firebrick jack-arching formed the floor of the tank, under which was situated the regenerator.

The sandstone course was laid in August I9I3, and taken down in November I92r, during which operation the structure was observed.
When emptying the tank the floor failed, and the glass discharged itself through a space between the floor and the regenerator roof. Thus while the walls were rapidly chilled the floor was maintained at a comparatively high temperature.

The accompanying photograph (Fig. I) is of one typical fragment taken from the inner surface ; other portions showed curvature of the columns, which at

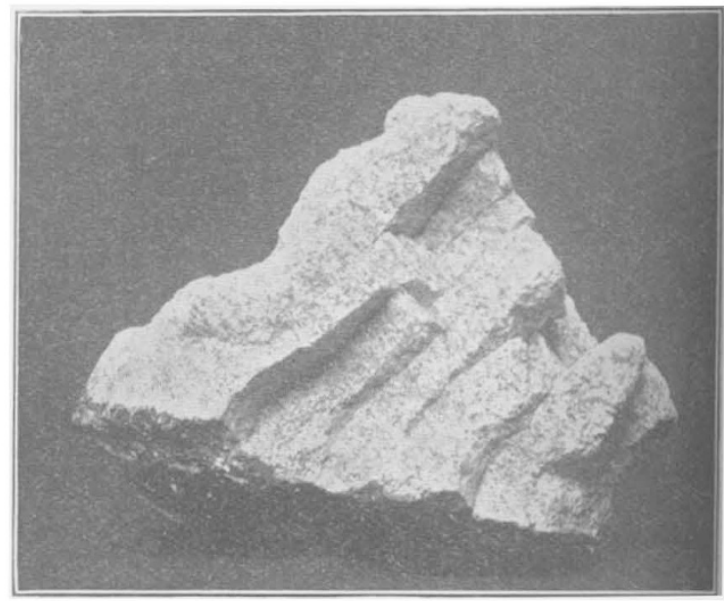

FIG. I.

the upper end were nearly normal to the corroded $\wedge$-shaped surface of the joint, and at the lower to the bottom surface of the block.

The similarity between these sandstone specimens and those of optical glass previously illustrated is worthy of remark.

Anniesland, Glasgow, February I3.

\section{The Action of Sunlight: A Case for Inquiry.}

READERS of NATURE are no doubt aware that the Medical Research Council has just appointed a Committee on the action of light upon the human body in health and disease, thus meeting the need which I have been allowed to urge in these columns under the above heading (NATURE, December 8, I92 I, and January 5).

I see no end to the inquiries in which we are now at last to participate in England, the country the smoke-darkened cities of which need them most. Before me now is a series of papers which I owe to Dr. A. F. Hess, of New York, who has demonstrated that sunlight can cure or prevent rickets in human infants and animals irrespective of the absence or presence of the supposed anti-rachitic vitamin. Again, along this coast, from Cannes to San Remo, I find French and Italian clinicians at work curing what I have called the diseases of darkness by sunlight; also a voluminous literature, as yet entirely unknown in England, which raises questions of high racial, genetic, and eugenic importance, such as the influence of sunlight, or the lack of it, upon the normal development of the reproductive system and its functions during adolescence. But clinicians elsewhere had assured me-and I fear I may have repeated their statements in these columns that the sun-cure cannot be practised on the Riviera!

Never henceforth, I predict, will the columns of NATURE cease to bear records of the new study of the biology of light now to be begun. C. W. SaleEby.

Hôtel Royal Westminster, Menton, February 19. 